\title{
A HISTÓRIA DE KAMO- NO CHÔMEI E A HISTÓRIA - DE 1155 A 1180
}

RESUMO: Pretende-se, no presente trabalho, abordar de modo cronológico, a interface entre a vida de Kamo- no Chômei e a época histórica em que viveu, buscando destacar fatos históricos, sociais ou pessoais que poderiam ter influenciado, de algum modo, sua vida literária. O veio literário de Chômei será analisado principalmente através de referências à obra $H o \hat{j} j \hat{o} k i$, na qual o autor busca respostas para seus questionamentos existenciais.

ABSTRACT: This paper has the purpose to consider in a chronological way the interface between Kamo- no Chômei's life and the historical period he has lived, specially emphasyzing historical, social and personal occurences that could have influenced, by some way, his litterary life. His litterary characteristic will be analysed through references of his work Hôjôki, in which the author looks for answers to his existencial questions.

PALAVRAS-CHAVE: Kamo- no Chômei, literatura e história, Hôjôki.

KEYWORDS: Kamo- no Chômei, Literature and History, Hôjôki.

Kamo- no Chômei (ou Kamo- no Nagaakira) foi poeta, prosador, músico e, nos últimos anos de sua vida, um inja (retirado budista). Nasceu numa família ligada tradicionalmente ao xintoísmo, deste se afastando, por imposição do destino. Desde sua juventude, Chômei dedicou-se à música e à atividade poética, tendo, respectivamente, como mestres Nakahara Ariyasu e Minamoto- no Shun'e. Seus poemas acham-se reunidos na antologia Kamo-no Chômeishû (Antologia de Kamo- no Chômei), compilada por volta de 1181. Em 1188, teve um poema selecionado para a antologia poética imperial Senzai Wakashû. Chômei participou de diversas competições poéticas (utaawase), e o seu reconhecimento como poeta legitima-se quando é nomeado pelo ex-imperador 
Gotoba como um dos membros do Departamento de Poesia da Corte (Wakadokoro), em 1201. Já retirado da sociedade e seguindo os caminhos de Buda, Chômei tem dez dos seus poemas incluídos em Shinkokin Wakashû, a antologia poética imperial, que conta entre seus organizadores com o poeta Fujiwara- no Sadaie (Teika).

Nascido exatamente numa época de transformações político-sociais em que ficava cada vez mais evidente a supremacia dos guerreiros bushi e o enfraquecimento da nobreza Heian, Chômei, assim como outros de sua época, opta por uma vida em reclusão, tendo sido sua fase madura voltada para atividades religiosas e literárias, em seu retiro de Toyama. Nos últimos quatro ou cinco anos de sua vida, concluiu suas obras em prosa Hôjôki, Mumyôshô e Hosshinshû. Chômei morreu num ano bissexto, 1216, no dia 8 de junho. Buscaremos, a seguir, acompanhar sua trajetória existencial e literária, através do destaque de fatos históricos que, direta ou indiretamente, tiveram influência sobre ela.

\section{Ano 2 da Era Kyûju (1155) - Provável Data de Nascimento de Chômei}

Heiankyô, "capital da paz" situada na atual Quioto, foi estabelecida pelo imperador Kanmu (reinou de $781 \sim 805$ ), em 794, tendo sido capital do Japão até 1868 (excetuando-se a mudança temporária realizada por Taira- no Kiyomori, em 1180), quando é substituída por Tóquio, pelo imperador Meiji. Nessa sua longa jornada, foi sem dúvida durante a época Heian (794 1192), que Heiankyô viveu seus tempos áureos como centro político e cultural. Embora não haja registros de sangrentas batalhas durante a época Heian, sendo, portanto, considerada uma época de relativa paz, sabese que não faltaram inúmeras disputas entre clãs da alta nobreza, bem como uma mudança gradual do próprio sistema político que era baseado no regime de códigos, ritsuryôsei, implantado ainda no período Nara (710 794), para um novo sistema de governo imposto pela classe emergente dos guerreiros, a partir de 1192, quando Minamoto- no Yoritomo funda o bakufu, o governo militar, em Kamakura.

A primeiras insurreições dos guerreiros ocorrem na primeira metade do século X. Conhecidas como Jôhei / Tengyôno ran (Revoltas de Jôhei e Tengyô) referem-se às revoltas lideradas por Taira- no Masakado, na região leste e por Fujiwara- no Sumitomo, no Mar de Seto, a oeste do país. Ambas foram derrotadas pelas forças do governo, Masakado, em 940 e Sumitomo, em 941 . Embora tivessem sido inssurreições regionais ocorridas de forma isolada, não deixaram de causar temor às autoridades centrais, por terem sido quase simultâneas em regiões opostas do país.

\section{Ano 1 da Era Hôgen (1156) - Revolta de Hôgen (Idade do Autor: 2 anos)'}

A Revolta de Hôgen eclodiu em Heiankyô, em 1156, envolvendo membros do clã Fujiwara e da família imperial, aliados a grupos guerreiros. A rivalidade entre

1. A idade que vem entre parênteses indica a idade do autor, e é baseada no kazoedoshi, método de cálculo de idade, segundo o qual, o ano de nascimento é contado como o primeiro ano de vida, somando-se mais um, a cada novo ano. 
Fujiwara- no Yorinaga e seu irmão Tadamichi, e entre o imperador Goshirakawa e seu irmão, o ex-imperador Sutoku, culminaram com a formação de dois grupos, Yorinaga e Sutoku aliados a Minamoto- no Tameyoshi e Taira- no Tadamasa contra Tadamichi e Goshirakawa aliados a Minamoto- no Yoshitomo (filho de Tameyoshi) e Taira- no Kiyomori (sobrinho de Tadamasa). O grupo do ex-imperador Sutoku é derrotado e ele é desterrado para Sanuki (atual província de Kagawa). Yorinaga é morto em combate, Tameyoshi e Tadamasa são executados. Embora este conflito tenha sido causado por uma disputa de poder no interior da nobreza, tornaram-se evidentes, por um lado, a sua fragilidade, e por outro, o poder cada vez maior dos grupos guerreiros.

\section{Ano 1 da Era Heiji (1159) - Revolta de Heiji (5 Anos)}

A Revolta de Heiji ocorreu também em Heiankyô, ocasionada pela disputa de poder entre Taira- no Kiyomori e Minamoto- no Yoshitomo. Aliados da facção vencedora da Revolta de Hôgen, Kiyomori e Yoshitomo começam a despontar no cenário político da época. Kiyomori, com admirável habilidade política, busca elevar-se no grau hierárquico, com a ajuda de Fujiwara- no Michinori (Shinzei), homem de confiança do ex-imperador Goshirakawa. Yoshitomo, por seu lado, une-se a Fujiwara- no Nobuyori, desafeto de Michinori e busca derrubar Kiyomori. Aproveitando a ausência de Kiyomori, em visita ao santuário Kumano, Yoshitomo mata Shinzei e aprisiona o ex-imperador Goshirakawa. Devido, no entanto, à pronta ação de Kiyomori, as forças de Yoshitomo acabam sendo derrotadas. Nobuyori é executado, Yoshitomo morto durante a fuga e seus filhos menores, entre eles, Yoritomo, futuro xôgun, são desterrados para regiões distantes. Os Minamoto permanecem, assim, ausentes por longo tempo do cenário político, passando a imperar a era dos Taira.

\section{Ano 1 da Era Ôhô (1161) - Distinção de 5. Grau Inferior Menor a Chômei (7 Anos)}

A “Distinção da Imperatriz". Chûgû joshaku, era uma honraria requerida à Corte em nome da imperatriz, e era conferida a distinção de $5^{\circ}$. grau nobiliárquico àquele cujo nome fosse por ela indicado. A indicação implicava, por parte do escolhido, a doação de tributos que consistia, provavelmente, numa parte da renda anual da imperatriz que tinha a permissão de fazer a indicação uma vez por ano. A escolha naturalmente era determinada por condições diversas como o mérito, ser membro de famílias próximas ao círculo de relações da imperatriz ou as vantagens obtidas. Presume-se, portanto, que na indicação de Chômei, tenham sido levadas em conta essas condições. A distinção de Chômei que, na ocasião, contava sete anos, ocorreu um ano depois de seu pai Nagatsugu ter recebido da Corte a distinção de $5^{\circ}$. grau maior inferior num dia e de $4^{\circ}$. grau menor inferior, no dia subseqüente.

A "Distinção da Imperatriz" foi concedida a Chômei pela imperatriz Shushi, filha do ex-imperador Toba. Shushi casou-se, aos 16 anos, com o príncipe Morihito. 
Depois da entronização do príncipe, como imperador Nijô, Shushi recebeu o título de chûgû, consorte imperial, em 1159. Em agosto de 1160, é acometida de uma grave enfermidade e realiza shukke, conversão religiosa. Em 1162, passa à categoria de nyôin. ex-imperatriz, sendo chamada de Takamatsuin, "ex-imperatriz Takamatsu"

\title{
5. Ano 2 ou 3 da Era Shôan (1172 1173)-Morte de Nagatsugu, Pai de Chômei (18 19 anos)
}

\author{
Composto diante da cerejeira, no ano seguinte à morte de meu pai \\ harushi areba vem a primavera \\ kotoshimo hanawa neste ano de novo flores \\ sakinikeri de mil cerejeiras \\ chiruo oshimishi onde estaria aquele homem \\ hitowa izurawa chorando o despetalar?
}

O poema acima encontra-se incluído na Antologia de Kamo- no Chômei (Kamono Chômeishû), e conforme a epígrafe, traz as lembranças do pai, morto no ano anterior. A chegada da primavera e o desabrochar da cerejeira evocam momentos passados com o pai, o que torna sua ausência ainda mais dolorida, diante da natureza cíclica das estações que se repetem a cada ano. O desnorteamento de Chômei diante do mistério da existência humana, "onde estaria aquele homem / chorando o despetalar?" é encontrado também no seguinte trecho de sua obra Hôjôki: "Ignoro. De onde vem e para onde vai, o homem que nasce e morre?"

Pouco se conhece sobre a vida de Kamo- no Nagatsugu, pai de Chômei, ou de sua relação com o filho. $\mathrm{O}$ pouco que se conhece diz respeito tão somente às suas atividades como sacerdote xintoísta. Segundo registros encontrados em livros de genealogia do santuário Kamo ou nos diários deixados por nobres da época, é possível delinear o seguinte perfil de Nagatsugu:

1- Nagatsugu foi sacerdote do santuário Tadasu, agregado ao santuário Kamo, ainda bastante jovem, durante o reinado do imperador Konoe (reinado, $1141 \sim 1155$ ):

2- ascendeu ao cargo de sacerdote chefe do santuário Shimokamo;

3 - em 27 de agosto de 1160, quando contava 22 anos, recebeu a distinção de $5^{\circ}$. grau superior menor, e no dia seguinte, a de $4^{\circ}$. grau inferior menor;

4- em registros de 1168, o nome de Nagatsugu (30 anos) é citado diversas vezes como sacerdote chefe do santuário Shimokamo, que representava outros santuários agregados;

5- o registro do dia 14 de agosto de 1169 de Heihanki, diário de Taira- no Nobunori, diz que Kamo- no Sukemitsu fora nomeado para um cargo, recomendado por Nagatsugu;

6- o registro do dia 29 de agosto de 1169, também de Heianki é o último conhecido a respeito de Nagatsugu (31 anos);

7- a partir de 1173, os registros trazem o nome de Kamo- no Sukesue no cargo anteriormente ocupado por Nagatsugu. 


\section{Ano 2 da Era Angen (1175) - Participação na Competição Poética Promovida pela Ex-imperatriz Takamatsu (21 Anos)}

Como evento marcante do ano, destaca-se a participação de Chômei na competição poética, denominada Kikuawase (Encontro do crisântemo), promovida pela ex-imperatriz Takamatsu. Em sua obra Mumyôshô (Escritos sem nome, 1212), Chômei faz referência ao fato, no episódio 5 denominado Hareno utawa hitoni misubeki koto (Poemas a serem apresentados em ocasiões formais devem ser previamente mostrados a alguém). Convidado a participar do Encontro do crisântemo, onde os grupos, divididos em direita e esquerda, apresentam seus poemas junto à uma flor de crisântemo para serem avaliados, Chômei compõe e mostra ao poeta Shômyô Nyûdô:

$\begin{array}{ll}\text { Sekikanuru } & \text { barrar impossível } \\ \text { namidano kawano } & \text { rio de lágrimas saudosas } \\ \text { seo hayami } & \text { correndo ligeiro } \\ \text { kuzurenikerina } & \text { destruindo as barragens } \\ \text { hitome tsutsumiwa } & \text { desvelando tal paixão! }\end{array}$

Segundo consta em antologias dos poetas que estiveram presentes nessa competição, como Minamoto- no Arifusa, cada participante deveria compor três poemas sobre os temas uchûno kusabana (erva daninha sob a chuva), tokoroni yorite tuki akashi (a lua é brilhante conforme o lugar) e sekiwo hedatsuru koi (amor além da fronteira). $\mathrm{O}$ poema destacado em Mumyôshô foi composto segundo o último tema, cantando a saudade de uma paixão secreta, já irrefreável. Tão forte quanto a rápida correnteza que destrói barragens, lágrimas de saudades correm qual rio, denunciando tal paixão secreta.

Shômyô Nyûdô, poeta renomado e antigo conhecido de seu pai, no entanto, apontou uma grave falta no poema. A palavra kuzuru, "destruir, desmoronar" utilizada no penúltimo verso, é grafada com o mesmo ideograma da palavra hôzu, "morrer". utilizada para indicar a morte de imperadores ou imperatrizes. Seria de um mau gosto terrível se Chômei declamasse tal poema justamente num evento realizado na residência da eximperatriz. Fora uma advertência providencial, pois, no ano seguinte à realização do Encontro, a ex-imperatriz Takamatsu, que o promovera, falece. Assim, seguindo os conselhos de Shômyô Nyûdô, Chômei substituíra o poema, e pudera participar do Encontro sem provocar qualquer constrangimento. Shômyô Nyûdô é o nome religioso de Fujiwara- no Chikashige, filho de Chikakata, governador provincial de Sado. Estava com 64 anos, por ocasião do episódio acima citado. Chegou a ser nomeado governador provincial temporário de Mino (parte da atual provícia de Gifu), com o título de $5^{\circ}$ grau inferior maior, mas afastou-se das atividades sociais, realizando a conversão religiosa.

\section{Ano 2 da Era Angen (1176) - Morte da Ex-imperatriz Takamatsu (22 Anos)}

A morte da ex-imperatriz ocorreu no dia 13 de junho de 1176, no ano seguinte à realização do Encontro do crisântemo, realizado sob seus auspícios. Coincide com o 
ano em que se comemorou em grande estilo os 50 anos do ex-imperador Goshirakawa (1127 1192). Foi uma festa que se prolongou por três dias, a partir do dia 4 de março. Estiveram presentes em Hôjûjiden, residência de Goshirakawa, o imperador Takakura e a nata da aristocracia de então, merecendo um especial destaque o clã Heike, aliado de Goshirakawa tanto na Revolta de Hôgen quanto na de Heiji. O imperador Takakura era filho de Goshirakawa e de Shigeko, cunhada de Taira- no Kiyomori, responsável pela ascensão política do clã Heike. Shigeko, conhecida também como Kenshunmon'in, faleceu em 8 de julho, com 35 anos de idade. Segundo consta em registros e diários da época, a enfermidade e a morte de Shigeko, tida como o elo de concórdia entre o eximperador Goshirakawa e o clã Heike, possui um peso significativo na história política do período na medida em que, a partir do seu desaparecimento, começam a surgir fissuras no relacionamento entre o ex-imperador e os Heike, culminando com o incidente de Shishigatani, no ano seguinte.

Nesse aspecto, a morte da ex-imperatriz Takamatsu, que faleceu com 36 anos, tão jovem quanto Shigeko, quase não teve repercussão, a ponto de o ex-imperador Goshirakawa, que era seu meio-irmão e sogro (a ex-imperatriz Takamatsu foi consorte imperial do imperador Nijô, filho de Goshirakawa), ter-se surpreendido, pois desconhecia totalmente a gravidade de sua doença.

\section{Ano 3 da Era Angen (1177) - Grande Incêndio (23 Anos)}

Devido à morte de Kenshunmon'in, no ano anterior, não foram realizadas as cerimônias em comemoração ao Ano Novo, como Shihôkei ${ }^{2}$ ou Kochôhai ${ }^{3}$, por encontrarem-se no período de luto conhecido por ryôan, quando o imperador perde um dos genitores. Durante a epidemia de varíola ocorrida no mês de fevereiro, o imperador Takakura acaba acometido pela doença. $\mathrm{O}$ clima sombrio parecia anunciar a chegada de um ano difícil.

Em março, eclode a revolta dos monges do templo Enryakuji. Tudo começara com a nomeação dos irmãos Minamoto- no Morotaka e Morotsune, respectivamente para governador e representante do governador de Kaga (parte da atual província de Ishikawa). Opressores ao extremo, não respeitavam outras leis, que não as próprias. Especialmente Morotsune tornou-se alvo de ira dos religiosos do templo Ugawadera, por ter invadido e cometido atos de violência, tão logo chegara a Kaga, e posteriormente, ter atacado e incendiado o templo com seus homens. O templo Ugawadera era uma das sucursais do templo Shirayama Gongen que, por sua vez, estava ligado ao templo Enryakuji. Dessa forma, um incidente ocorrido numa remota província acabou tendo repercussões na capital, quando, em 21 de março, os monges do templo Enryakuji

2. Cerimônia de Ano Novo em que o imperador dirige-se para o jardim leste do palácio, faz reverências em direção aos quatro pontos cardeais e ora para as divindades, pedindo paz e felicidade, no decorrer do novo ano.

3. Cerimônia de Ano Novo em que os altos dignatários e a elite nobiliárquica fazem os cumprimentos do Ano Novo ao imperador. 
exigiram o desterro de Morotaka. A corte imperial decidiu pelo exílio de Morotsune, que foi enviado para Bingo (parte da atual província de Hiroshima). Não satisfeitos, os monges insistiram no desterro de Morotaka e realizaram uma manifestação, adentrando na capital com o palanquin sagrado. Os monges foram rechaçados por Taira- no Shigemori e seus homens. Durante o conflito, flechas perdidas acabaram acertando o palanquim, levado pelos monges como um símbolo sagrado intocável. No dia seguinte, informado de que ocorreria um ataque dos monges, o imperador transferiu-se para Hôjûjidono. Ele acabou por ordenar o exílio de Morotaka para a região de Owari (parte da atual província de Aichi) e a prisão dos arqueiros que atingiram o palanquim, encerrando o conflito, mas no mês seguinte, a tensão entre a corte e o templo voltou a agravar-se, devido à destituição de Myôun 1115-1183) de seu cargo de monge chefe e de seu exílio para Izu, sob a acusação de ser o responsável pelo incidente de Enryakuji. Myôun foi resgatado pelos monges guerreiros quando era levado para Izu.

Por ter ocorrido em meio ao conflito dos monges de Enryakuji, o incidente foi tomado como um acontecimento extraordinário. Na narrativa 16, tomo I, "O incêndio do palácio", de Heike Monogatari (Narrativas do clã Taira), por exemplo, consta que o grande incêndio foi considerado uma punição da divindade Sannô Gongen, tendo várias pessoas sonhado, na ocasião, com a chegada de dois a três mil macacos que desciam do monte Hiei com tochas na mão.

O grande incêndio aconteceu na noite de 28 de abril e está descrito em Hôjôki da seguinte forma:

Foi, penso eu, no terceiro ano da Era Angen, no dia 28 de abril. Numa noite inquietante, de fortes ventos, perto das oito horas, o fogo teve início a sudoeste da capital, e alcançou a parte noroeste. Acabou atingindo o Portal Suzaku, o Palácio Daikoku, a Escola Superior dos Nobres, o Ministério dos Assuntos Civis que, numa noite, transformaram-se em cinzas.

Diziam que o fogo teve origem no beco Higuchitomi, de uma estalagem provisória de dançarinos. À mercê do vento que soprava sem rumo, o fogo alastrou-se em forma de leque, ampliando cada vez mais o seu raio de ação. As casas ao longe pareciam soltar fumaça, e as que se encontravam próximas ao foco do incêndio golfavam violentas labaredas em direção ao solo. No céu, as cinzas sopradas pelo vento refletiam o brilho do fogo; em meio ao céu carmim, chamas carregadas pelo vento seguiam queimando uma, duas quadras adiante. Que momentos terríveis não teriam passado as pessoas cercadas por aquelas chamas? Algumas tombaram sufocadas pela fumaça, outras sucumbiram instantaneamente envoltas pelo fogo. Ou ainda outras alcançaram escapar só com a roupa do corpo, impossibilitadas de salvar qualquer bem material. Preciosos tesouros transformaram-se em cinzas. De quanto teria sido o prejuízo? Nesse incêndio foram perdidas dezesseis residências da nobreza. Demais moradias, impossível saber o número. Conta-se que terça parte da capital foi destruída pelo fogo. Houve dezenas de mortos entre homens e mulheres e quanto a animais como cavalos ou bois, incontáveis.

Há vários empreendimentos inúteis realizados pelo homem, mas não vejo inutilidade maior do que dispender a fortuna e passar por sofrimentos, construindo casas num local tão perigoso como a Capital. 
Segundo anotações de Gyokuyô $\hat{}^{4}$, diário de Kujô Kanezane (1149-1207), no dia 28, o céu estava aberto, mas escuro, pois a lua era minguante. Quanto ao horário, consta em Hôjôki que o incêndio teve início por volta das oito horas, diferentemente das demais fontes que registram o início como tendo ocorrido por volta das dez horas. Seja como for, presume-se que as labaredas teriam adquirido um aspecto muito mais assustador numa noite de tênue claridade. $\mathrm{O}$ foco do incêndio teve origem no beco Higuchitomi, mas a causa é desconhecida. Segundo registro do funcionário do Departamento de Polícia, os dados mais detalhados e confiáveis são os encontrados em Seikaiganshô e Gyokuyô, mas não há qualquer referência às causas do incêndio.

A edição Daifukukôjibon de Hôjôki registra que o fogo espalhou-se a partir de uma estalagem de "dançarinos" (maibito), enquanto todas as outras edições trazem "enfermos" (yamaibito). A existência ou não da sílaba "ya" explica tal diferença, mas determinar qual deles seja o correto torna-se muito difícil. (A tradução utilizada no presente trabalho encontra-se baseada na edição Daifukukôjibon, razão pela qual utilizamos "dançarinos".) Sabe-se que o beco Higuchitomi estava localizado numa área inóspita, próxima à famosa residência Kawaranoin construída por Minamoto- no Tooru (822-895) e que, à época, encontrava-se totalmente em ruínas.

Alimentado pelo forte vento, o fogo foi tomando a Capital em forma de leque, rumo à direção do palácio imperial. Segundo anotações de Gyokuyô, Kanezane encontrava-se, naquela noite, na sua residência e vira sinais de fogo ao norte, mas recolherase sem lhe dar maior importância, pois pequenos incêndios eram freqüentes naquele tempo. Pela manhã, foi informado de que, embora a residência imperial não tivesse sido atingida, o fogo chegara a destruir parte do palácio, e que o casal imperial refugiarase na residência do Alto Conselheiro Kunitsuna, em Ôgimachi Tôin, uma área que estaria a salvo. Segundo ainda registro de Kanezane, o Palácio Daikoku, bem como as edificações próximas a ele sofreram as ações do fogo e quatorze (segundo Hôjôki, seriam dezesseis) residências aristocráticas foram danificadas.

Este incêndio foi considerado o primeiro de proporções tão devastadoras, desde a construção da capital Heian, vítima de inúmeros incêndios menores, conforme citado anteriormente. Seikanganshô (inserido na parte referente aos assuntos da corte de Gunshoruijû), escrito no início da época Kamakura, traz a relação de algumas das edificações e residências destruídas pelo fogo: as edificações Daigakuryô, Ôtenmon, Shingon'in, Aishômon, Daikokuden, Jingikan, Daizenshiki, Shikibushô, Uhyôefu, Suzakumon, Kangakuin, entre outras e as residências de altas autoridades como Kanpakudono Fujiwara- no Motofusa, Naidaijin Fujiwara-no Moronaga, Alto Conselheiro Sanesada, Alto Conselheiro Sadakuni, Alto Conselheiro Takasue, Nii Chûjô Kanefusa, Alto Conselheiro Kunitsuna, Médio Conselheiro Sukenaga, Bettô Chûnagon Tadachika, Médio Conselheiro Masayori, Tô Chûnagon Sanetsuna, Udaiben Sanmi Toshitsune, Tô Sanmi Toshimori.

O Portal Suzaku era a entrada principal do palácio imperial. Localizava-se na extremidade norte da Avenida Suzaku, que cortava o centro da capital no sentido norte-

4. Os dados constantes nos diários dos nobres utilizados no presente trabalho encontram-se baseados no trabalhos de S. Miki, Kamo- no Chômei. Tóquio, Kôdansha, 1995. 
sul. Dentre as edificações atingidas pelo fogo, a destruição do Palácio Daikoku, edifício central do palácio e onde o imperador realizava suas funções oficiais, parece ter sido a que maior impacto causou à corte. Em 4 de agosto do mesmo ano, foi publicado o édito imperial mudando a denominação da era, de Angen para Jishô. Segundo Gyokuyô (anotação do dia 4 de agosto de 1177), no édito imperial consta que a destruição do Palácio Daikoku teria sido a principal causa dessa mudança. A destruição, assim, de importantes símbolos como o Portal Suzaku ou o Palácio Daikoku pode ter contribuído para o mito da punição, marcando também a decadência da "reluzente Capital" citada por Chômei no início de Hôjôki.

\section{Ano 4 da Era Jishô (1180) Tornado - Mudança da Capital para Fukuhara - Levante Militar do Clã Minamoto (26 Anos)}

O grande incêndio de 1177 vai marcar o início não só das calamidades naturais, como também é seguido por uma série de agitações sociais marcantes.

$\mathrm{Na}$ sombra da repercussão do incidente de Enryakuji, assiste-se ao crescimento dos movimentos anti-Heike. No mesmo ano de 1177, um desses movimentos, que ficou conhecido como a Conspiração de Shishigatani, pois as reuniões do complô eram realizadas na residência de um dos membros, localizada no local de mesmo nome, sofre um grande golpe. O grupo intentava atacar Rokuhara, base dos Heike, mas o plano acaba sendo delatado por um dos membros. Como consequêencia, seus principais mentores, ligados ao ex-imperador Goshirakawa, foram executados ou exilados. Embora Taira- no Kiyomori não tivesse tomado uma atitude mais direta contra o ex-imperador, suas relações foram se tornando cada vez mais difíceis. Após a morte de Shigemori (1138-1179), filho herdeiro de Kiyomori, Goshirakawa tomou as propriedades deixadas pelo primeiro, o que o levou o levou a sofrer ações militares e a se encerrar no palácio Tobadono. Além disso, Kiyomori substituiu todos os cargos de confiança, nomeando membros do clã ou homens a ele fiéis, dando início a seu governo despótico. Kiyomori adota uma política de rígido controle, espalhando espiões pela Capital e punindo duramente os conspiradores.

Cabe lembrar, ainda, que Kiyomori buscava controlar o país não somente através da força militar, mas também garantindo sua legitimidade. Em 1178, sua filha, Kenreimon'in (Taira- no Tokuko), esposa do imperador Takakura, dá à luz Tokihito (11781185), príncipe herdeiro que ascende ao trono em 1180 com o nome Antoku, com apenas dois anos de idade e morre, em 1185, na batalha final dos Heike em Dannoura, nos braços de sua avó, que se atira ao mar.

Outro fato a ser lembrado é o levante dos Minamoto que haviam sido derrotados pelos Heike, na Revolta de Heiji, em 1159. Em 1180, no dia 9 do quarto mês, o príncipe Mochihito (1151-1180), terceiro filho de Goshirakawa, envia uma ordem nacional de levante contra os Heike. A ordem chega até Minamoto- no Yoritomo, filho de Yoshitomo, em Izu, no dia 27 do mesmo mês. O tornado descrito por Chômei em Hôjôki, ocorre dois dias depois, nesse clima de tensão, e passados três anos do grande incêndio. $\mathrm{O}$ tornado é descrito em Hôjôki da seguinte maneira: 
Então, novamente, por volta do mês do coelho, do quarto ano da era Jishô, da altura do cruzamento entre as avenidas Nakamikado e Kyôgoku, soprou um forte tornado que se alastrou até as proximidades da avenida Rokujô.

Enquanto ia varrendo, três, quatro quadras, carregava junto as casas que encontrava pela frente, não restando uma só, grande ou pequena, que não tivesse sofrido danos. Algumas simplesmente desabaram e foram ao chão, outras, restaram só com vigas e colunas. $\mathrm{O}$ tornado carregou portões a quatro ou cinco quadras ou derrubou cercas que delimitavam terrenos vizinhos.

Segundo Meigetsuki, diário de Fujiwara- no Teika, houve por volta das duas horas da tarde, uma precipitação de granizo, seguido por dois ou três trovões e violentos raios. Via-se fumaça na direção norte e, a princípio, pensou-se num incêndio. Na realidade, tratava-se de um tornado.

Assim como no caso do incêndio, Chômei consegue descrever o tornado como algo extremamente próximo do leitor, privilegiando não só o aspecto visual através dos objetos lançados ao ar pelo vento, mas também o auditivo, chamando a atenção para o som estrondoso do tornado. O que se destaca em meio a esse cenário de destruição é a força aniquiladora da natureza e a infinita fragilidade do ser humano.

Após o envio da ordem de levante contra os Heike, o príncipe Mochihito e Minamoto- no Yorimasa (1104-1180) juntam forças para derrotá-los. Alcançam o templo Onjôji, na atual provícia de Shiga, mas acabam sendo derrotados pelas forças de Kiyomori. Embora tenha sufocado o levante, Kiyomori dá-se conta de que a situação não lhe era tão favorável, e toma duras ações contra os templos inimigos, tomando-lhes as propriedades de onde provinha o seu sustento. A transferência da Capital para Fukuhara, em 1180, fora a forma encontrada por Kiyomori de manter distância das forças religiosas de Heiankyô, embora o motivo alegado fosse a busca da pacificação. Conforme contanos a história, a ordem de Mochihito desencadeia uma série de levantes pelo país, dando início a uma guerra civil que termina com a eliminação do clã Heike, em 1185.

O leitor de Hôjôki sabe que Chômei não faz qualquer referência a todo esse processo histórico quando trata da mudança da Capital. Ele preocupa-se, antes, em enfatizar o caráter extraordinário do fato, relacionando-o ao princípio da transitoriedade. Diferentemente das demais catástrofes de ordem natural citadas em Hôjôki (incêndio, tornado, fome e terremoto), esta é a única ocasionada por questões sociais e a única em que não se dá destaque à destruição de Heiankyô. Pelo contrário, o que se vê é a nítida contraposição entre as duas capitais, a atual e a antiga. Fukuhara é descrita como topograficamente inadequada, sem a beleza e a refinada elegância de Heiankyô em seus áureos tempos, e seus moradores são comparados a guerreiros provincianos. Mesmo que Heiankyô tenha deixado de ser a "reluzente Capital" de outrora, seus tempos de glória continuam sendo lembrados com nostalgia.

Embora não haja um registro da viagem de Chômei a Settsu, existem dois poemas em sua antologia Kamo- no Chômeishû que fazem referência a ela. O primeiro deles diz o seguinte:

Composto, no momento da partida para um lugar remoto, quando a patrínia da casa encontrava-se no auge do florescimento 

Arujiwato
se alguém perguntar
tou hito araba
o paradeiro do dono
ominaeshi
ó, patrínia em flor,
yadono keshikio
responde-lhe para ver
miyoto kotaeyo
a aparência da morada

Segundo Yanase 5 , o "lugar remoto" estaria se referindo à província de Settsu (parte das atuais províncias de Osaka e Hyôgo), tendo, portanto, o poema acima sido composto por ocasião da partida para Fukuhara, tese também aceita por Miki ${ }^{6}$. A expressão "lugar remoto" para indicar Fukuhara pode parecer inadequado segundo o parâmetro atual, mas considerando-se a época de Chômei, qualquer localidade fora dos limites da Capital poderia comportar tal acepção.

A patrínia (ominaeshi) costumava ser utilizada no poema como uma referência feminina e compõe o grupo das chamadas "sete ervas do outono" (akino nanakusa), juntamente com a lespedeza bicolor (hagi $)^{8}$, o capim-dos-pampas japonês (susuki) ${ }^{9}$. o eupatório (fujibakama $)^{10}$, a araruta $(k u z u)^{11}$ a cravina (nadeshiko) ${ }^{12}$ e a campânula chinesa $(k i k y \hat{o})^{13}$, ocorrendo o seu florescimento no sétimo mês do antigo calendário, o que nos leva a presumir que Chômei tenha ido para Fukuhara por essa época.

Confome obrservação de $\mathrm{Miki}^{14}$, Chômei utiliza-se da técnica conhecida como honkadori ("alusão poética"), fazendo alusão ao seguinte "poema original" (honka) de Ariwara-no Yukihira (818-893), poeta da época Heian:
wakurabani
se alguém perguntar
tou hito araba
sumano urani
por mim, responde-lhe assim:
moshio taretsutsu
"está em Suma ${ }^{15}$,
wabuto kotaeyo
verte pranto desolado
nas algas salgadas ${ }^{16}$ da praia

Este poema foi escrito por Yukihira, na ocasião em que se encontrava recolhido em Suma devido a um incidente em que se envolvera, e possui um tom de profunda melancolia e desolação. O poema de Chômei, composto no momento da partida, possui

5. K. Yanase, Kamo- no Chômei Shinkenkyû, Tóquio, Chûbunkan Shoten, 1938, p. 313.

6. S. Miki, Kamo- no Chômei, Tóquio, Kôdansha, 1995, p. 99.

7. Patrinia scabiosaefolia.

8. Lespedeza bicolor.

9. Miscanthus sinensis.

10. Eupatorium stoechadosmum.

11. Pueraria.

12. Dianthus superbus.

13. Platycodon grandiflorum.

14. Idem, p. 99.

15. Suma, praia localizada na atual cidade de Kobe, foi também o local de exílio de Hikaru Genji, protagonista de Genji Monogatari.

16. Refere-se à alga moshio, utilizada para a obtenção de sal, molhando-a com a água do mar (associada à lágrima) e, posteriormente, fervendo-a e decantando-a. 
um viés distinto, na medida em que a ida a Settsu foi uma viagem e não um "exílio" como no caso de Yukihira. A expectativa da viagem parece sobrepujar qualquer outro tipo de sentimento. É uma expectativa com relação ao que encontraria em outras paragens, ou mesmo ao que os que o procurassem pudessem pensar.

O segundo poema que faz referência à viagem de Chômei para Fukuhara teria sido composto durante a sua jornada:

Poema que escrevi, ao lado do exercício de caligrafia rabiscado na porta corrediça do quarto, na ocasião em que pernoitei na localidade de Koya, a caminho da província de Tsu

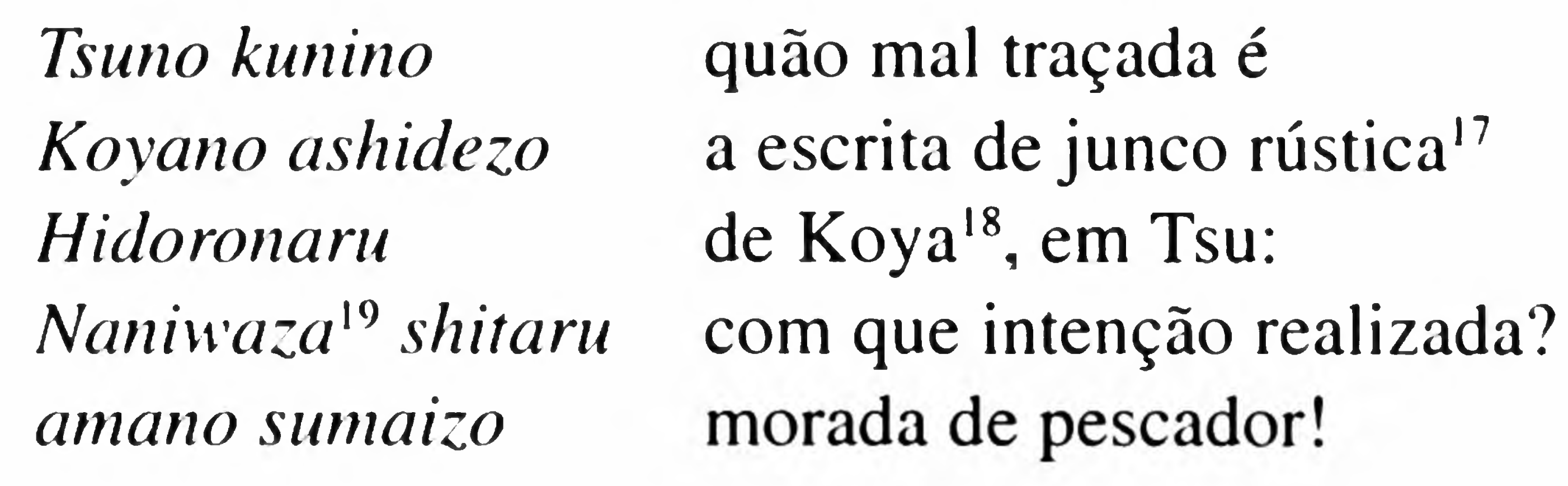

Segundo a epígrafe, este poema teria sido composto durante a viagem para a província de Settsu. Ao perceber alguns rabiscos, escritos à guisa de exercícios caligráficos, na porta corrediça da pousada, Chômei registra suas impressões de viagem. Estando fora da Capital, referência cultural absoluta da época, Chômei não pode deixar de notar a péssima caligrafia, cuja destreza fazia parte da formação das classes instruídas (clero e nobreza). Ao associar tal caligrafia mal escrita qual rabiscos que lembram o junco, através do jogo de palavras ashide (caligrafia-junco) e ashide (caligrafia ruim), Chômei faz alusão não só à inabilidade do manuscrito como também à rusticidade da pousada, comparando-a a uma casa de pescador.

A descrição da nova capital, encontrada em Hôjôki, coaduna com estas impressões:

Nessa época, devido a compromissos particulares, estive na nova capital de Tsu. Observando a sua topografia, constatei que o lugar era estreito, inadequado para comportar as dimensões próprias de uma capital. O norte era mais elevado, acompanhando as montanhas, o sul ficava próximo ao mar, portanto mais caído. O barulho das ondas soava ruidoso e a brisa do mar soprava especialmente forte. Estando o palácio imperial em meio à montanha, fazia-nos imaginar se aquele palácio de toras ${ }^{20}$ não teria tal aspecto, e esta inesperada rusticidade não deixava de ter sua elegância. [...] observando-se os arredores, aqueles que deveriam utilizar-se de carruagens estavam a cavalo, aqueles que deveriam estar trajados com o vestuário da nobreza usavam.

17. Expressão referente ao termo ashide, "escrita-junco", ou seja, estilo caligráfico cujos traços lembram o junco. Há um jogo de palavras com a expressão homófona ashide, "escrita mal traçada". Sabe-se que a região de Settsu possuía junco em abundância.

18. A localidade de Koya, na atual província de Hyôgo permite o trocadilho com o termo homófono koya, "não quer vir?". Koya é utilizado também como utamakura (topônimo poético), recurso poético amplamente utilizado pela poesia clássica.

19. Chômei faz um jogo de palavras entre naniwaza, "com que intenção?" e o topônimo Naniwa, denominação antiga da região de Osaka e cercanias e utilizado como topônimo poético da província de Settsu.

20. Relativo ao palácio provisório construído de toras naturais pela imperatriz Saimei (reinou entre 655661), em Chikuzen (atual Fukuoka), na ocasião em que para lá se dirigira, acompanhando os soldados em campanha contra Shiragi. 
em sua maioria, trajes próprios dos guerreiros. Os costumes da Capital modificaram-se repentinamente, em nada diferindo daqueles dos guerreiros provincianos.

Os rumores de que conturbações sociais estavam por vir iam-se confirmando com o passar dos dias, trazendo inquietação a todos. A apreensão da população acabou por se confirmar e, no inverno do mesmo ano, todos retornaram a esta Capital. Entretanto, qual teria sido o destino de todas aquelas casas desmontadas? Impossível reconstruí-las como dantes.

No trecho destacado, Chômei chama a atenção para a topografia do local, muito acidentado para comportar a construção de uma capital, pelo menos nos moldes de Heiankyô, uma planície situada no vale. Tanto Heiankyô como Heijôkyô, a primeira capital fixa, que ficava na atual cidade de Nara, foram construídas conforme os traçados da capital chinesa de Chang An. Isto significa que, desde o início do século VIII, a capital japonesa mantém o mesmo tipo de traçado. $O$ horizonte dos que moravam na Capital foi sempre a montanha, onde se localizavam os principais templos, diferentemente dos templos de Heijôkyô que ficavam no interior da própria capital. Cercados pelas montanhas, os moradores de Heiankyô não tinham qualquer intimidade com o mar, o que explica o incômodo causado pela maresia e o bater das ondas. Mas mais do que o espaço físico, é a mudança de costumes o que causa maior impacto em Chômei. A substituição das luxuosas carruagens de boi pelo cavalo e o uso do vestuário mais despojado em lugar da refinada indumentária da nobreza refletem a mudança dos tempos, do ritmo de vida, que segue agora mais veloz, acompanhando a nova classe emergente dos guerreiros bushi.

\section{Bibliografia}

KawaSe, Kazuma. Hôjôki. Tóquio, Kôdansha, 1971.

KuBOTA, Jun. "Kamo- no Chômei". In: Chûseino Bungaku (Literatura da Idade Média Japonesa). Tóquio, Yûhikaku, 1976, pp. 108-112.

Mıкı, Sumito. Hôjôki. Tóquio, Sanseidô, 1977.

Kamo- no Chômei. Tóquio, Kôdansha, 1995.

YanaSE, Kazuo. Kamo- no Chômeino Shinkenkyû (Novos Estudos sobre Kamo- no Chômei). Tóquio, Chûbunkan Shoten, 1938.

YASURAOKA, Kôsaku. Hôjôki. Tóquio, Kôdansha, 1996. 